\title{
Molecular basis of altered excitability in Shaker mutants of Drosophila melanogaster
}

\section{Ralf Lichtinghagen, Martin Stocker, Reilinde Wittka ${ }^{2}$, Günther Boheim², Walter Stühmer ${ }^{1}$, Alberto Ferrus ${ }^{3}$ and Olaf Pongs}

Ruhr-Universität Bochum, Lehrstuhl für Biochemie, 4300 Bochum, FRG, ${ }^{1}$ MPI für biophys. Chemie, Abt. Membranbiophysik, 3400 Göttingen, FRG, ${ }^{2}$ Ruhr-Universität Bochum, AG Biophys. Chemie von Membranen, Lehrstuhl für Zellphysiologie, 4630 Bochum, FRG and ${ }^{3}$ Instituto Cajal, 28002 Madrid, Spain.

Communicated by B.Sakmann

Mutations in the Shaker (Sh) locus of Drosophila melanogaster have differing effects on action potential duration and repolarization in neurons as well as on Atype $\mathrm{K}^{+}$channels $\left(I_{\mathrm{A}}\right)$ in muscle. The molecular basis of three exemplary $S h$ alleles $\left(S h^{\mathrm{KS} 133}, S h^{\mathrm{E} 62}\right.$ and $\left.S h^{5}\right)$ has been identified. They are point mutations in the $S h$ transcription unit expressing aberrant voltage-gated Atype $\mathrm{K}^{+}$channels. Replicas of each mutation have been introduced by in vitro mutagenesis into $S h$ cDNA. The expression of in vitro transcribed mutant $S h$ cRNA in Xenopus laevis oocytes reproduced the specific phenotypic traits of each $S h$ allele. The lack of $I_{\mathrm{A}}$ in $S h^{\mathrm{KS} 133}$ is due to a missense mutation within a sequence motif occurring in all hitherto characterized voltage-gated $\mathrm{K}^{+}$channel forming proteins. The reduction of $I_{\mathrm{A}}$ in $S h^{\mathrm{E} 62}$ is due to a mutation in an AG acceptor site. The intervening sequence between exons 19 and 20 is not spliced in $S h^{\mathrm{E} 62}$ RNA. As a consequence, $S h^{\mathrm{E} 62}$ flies do not contain the full complement of $S h \mathrm{~K}^{+}$forming proteins. Finally, the $S h^{5}$ mutation leads to an altered voltage dependence of $\mathrm{K}^{+}$channel activation and inactivation as well as to an accelerated rate of recovery from inactivation. This is due to a missense mutation altering the amino acid sequence of the proposed transmembrane segment $S 5$ of the $S h$ $\mathrm{K}^{+}$channels. Segment $\mathrm{S} 5$ is located adjacently to the presumed voltage sensor of voltage-gated ion channels. The results explain the altered properties of excitable cells in Sh mutants and provide a general model for the possible role of A-type $\mathrm{K}^{+}$channels in modulating action potential profiles.

Key words: action potential/A-current, splicing/potassium channel

\section{Introduction}

Action potentials are the rapidly propagated messages that speed along the axons of the nervous system and over the surface of excitable cells. The rising phase of the action potential corresponds to a transient inward current which is usually mediated by a flow of sodium ions through $\mathrm{Na}^{+}$ channels. The falling phase of an action potential is mediated by an outward current carried by potassium ions which flow through a variety of $\mathrm{K}^{+}$channels (Hille, 1984). The shape and frequency of action potentials underlie alterations of synaptic efficiency which in turn leads to an increase or to a reduction in presynaptic neurotransmitter release (Abrams and Kandel, 1988; Cros, 1988). Enhanced neuronal excitability is correlated with cellular events underlying associative learning and memory. In particular, $\mathrm{K}^{+}$ channels are involved in alterations of synaptic efficiency. Reduction in the activity of these channels leads to an increase in presynaptic neurotransmitter release reminiscent of a facilitated neurotransmitter release (Abrams and Kandel, 1988; Crow, 1988).

Since the Shaker (Sh) locus encodes a family of $\mathrm{K}^{+}$ channel forming proteins (Iverson et al., 1988; Timpe et al. 1988a,b) Sh mutants of Drosophila melanogaster are ideally suited to study the molecular basis of altered excitability caused by dysfunctional A-type $\mathrm{K}^{+}$channels. Sh mutants have an altered neuronal excitability due to abnormal action potential durations and repolarizations or to abnormal bursts of action potentials (Tanouye et al., 1981; Tanouye and Ferrus, 1985). Also, Sh mutants have impaired transient outward $\mathrm{K}^{+}$currents in muscle tissues (Salkoff, 1983; Wu and Haugland, 1985; Solc et al., 1987).

We have characterized three particular $S h$ mutants $\left(S h^{\mathrm{KS} 133}, S h^{\mathrm{E} 62}, S h^{5}\right)$ which are point mutations within the $\mathrm{K}^{+}$channel transcription unit. Each $S h$ mutant exhibits distinct alterations in the action potential profile measured in the cervical giant interneurons of D.melanogaster. The allele $S h^{\mathrm{KS} 133}$ shows action potentials with a long delay in their repolarization (Tanouye and Ferrus, 1985). In addition, A-channels in $S h^{\mathrm{KS} 133}$ muscle fibres appear to be absent (Solc et al., 1987). $S h^{\mathrm{E} 62}$ mutants exhibit repetitive, albeit irregular firing of action potentials (Tanouye and Ferrus, 1985 ) and a residual $I_{\mathrm{A}}$ in muscle fibres (Timpe and Jan, 1987). Finally, the allele $S h^{5}$ causes repetitive firing of burst shaped action potentials (Tanouye and Ferrus, 1985). $I_{\mathrm{A}}$ in muscle fibres is shifted to more positive potentials (Wu and Haugland, 1985) and the rate of recovery from $I_{\mathrm{A}}$ inactivation is accelerated (Salkoff, 1983).

Replicas of the mutants were introduced into cDNA by in vitro mutagenesis, in order to correlate the structural alteration in the mutant $S h \mathrm{~K}^{+}$channel with the altered Acurrents in muscle cells as well as with the altered action potential profiles in interneurons of $S h$ mutants. The cDNA replicas of the $S h$ mutants were transcribed in vitro into cRNA, the expression of which was studied after injection into Xenopus laevis oocytes. Properties of the mutant Sh $\mathrm{K}^{+}$channels were compared with those of wild type $S h \mathrm{~K}^{+}$ channels. The results show that phenotypic traits which have been described for each $S h$ mutant under study were reproduced in the X.laevis oocyte expression system. Thus, the abnormal excitability of $S h$ mutants is caused by structural defects in $\mathrm{Sh} \mathrm{K}^{+}$channel forming proteins. Implications of these results are discussed in the light of the role of A-type $\mathrm{K}^{+}$channels in modulating and shaping action potential profiles. 


\section{Results}

The members of the $\mathrm{K}^{+}$channel family which is encoded in the Shaker (Sh) locus share a common core region flanked by variant $\mathrm{N}$ - and C-terminal sequences (Kamb et al., 1988; Pongs et al., 1988; Schwarz et al., 1988). Therefore, two principally different types of mutations can occur within the coding region of the $S h$ transcription unit. Mutations alter either a sequence encoding one of the variant terminal ends or the sequence which encodes the core region of the $\mathrm{K}^{+}$ channel forming proteins. In the former case, only some members of the $\mathrm{K}^{+}$channel family should be dysfunctional, whereas in the latter case the entire $\mathrm{K}^{+}$channel family should have lost or altered its activity. Previously, we have shown that $S h^{102}$ mutation is a nonsense mutation in the $S h$ core region causing the production of truncated $\mathrm{K}^{+}$channel subunits (Gisselmann et al., 1989). This leads to a strong dominant $S h$ phenotype. The mutations $S h^{102}$ and $S h^{\mathrm{KS} 133}$ should reside in close proximity since they have not been

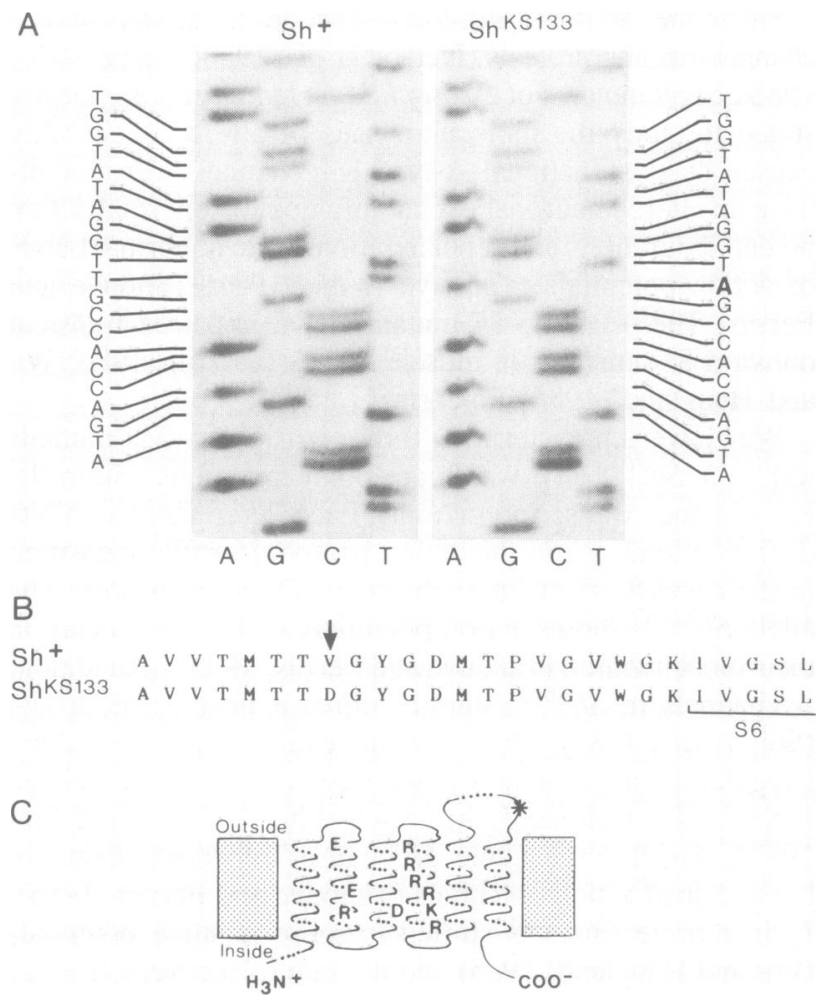

Fig. 1. Molecular basis of the mutation in $S h^{\mathrm{KS} 133}$ flies. (A) Part of the exon 15 sequence of the $S h$ transcription unit of Canton S DNA $\left(S h^{+}\right)$and of $S h^{\mathrm{KS} 133}$ DNA. The sequence corresponds to nucleotides 1276-1296 of Sh $\beta$ cDNA (Pongs et al., 1988). The T to A base change between wild type and mutant DNA is emphasized by a bold $\mathrm{A}$ in the $S h^{\mathrm{KS} 133}$ sequence on the right hand side. Wild type DNA of the $S h$ locus has been isolated and sequenced as described previously (Pongs et al., 1988). (B) Comparison of the derived $S^{+}$and $S^{\mathrm{KS}} 133$ amino acid sequences. The sequence is given in the standard one letter code. The sequence corresponds to amino acids $422-447$ in ShA2 protein (ShA2 is equivalent to $S h \mathrm{~B}$, Schwarz et al., 1988). The replacement of valine (V) by aspartic acid (D) in $S h^{\mathrm{KS} 133}$ proteins is indicated by an arrow and the beginning of proposed transmembrane segment S6 by a bracket. (C) Topological model of a Sh potassium channel subunit (Pongs et al., 1988) inserted into the membrane having the $\mathrm{N}$ - and $\mathrm{C}$-termini on the cytoplasmic side of the membrane. Charged amino acids within the six proposed transmembrane helices are indicated (D, aspartic acid; $\mathrm{E}$, glutamic acid; $\mathrm{K}$, lysine; $\mathrm{R}$ arginine). The asterisk in the model illustrates the location of the missense mutation in $S h^{\mathrm{KS} 133} \mathrm{~K}^{+}$channel subunits. separated by recombination (Kamb et al., 1987; Ferrus et al., 1990). Therefore, we entertained the hypothesis that the $S h^{\mathrm{KS} 133}$ mutation also resides in the $S h$ core region not far from the $S h^{102}$ mutation. A $S h^{\mathrm{KS} 133}$ genomic DNA library was constructed and the exons encoding the core region were subcloned and sequenced. The comparison of the $S h^{\mathrm{KS} 133}$ DNA sequence with that of the parental Canton $\mathrm{S}$ chromosome indicated a single base change ( $\mathrm{T}$ to $\mathrm{A}$ ) in exon 15 (Figure 1A). As a result, the derived $S h^{\mathrm{KS} 133}$ proteins would have the amino acid aspartic acid (GAT) instead of valine (GTT) (Figure 1B). The $S h^{\mathrm{KS} 133}$ missense mutation is located within the bend region connecting the proposed membrane spanning segments S5 and S6 (Figure 1C) according to the topological model of $\mathrm{K}^{+}$ channel subunits (Pongs et al., 1988). Thus, the $S h^{\mathrm{KS} 133}$ and $S h^{102}$ mutations are only separated by a small distance (27 bp) on the chromosome.

Electrophysiologically, $S h^{\mathrm{KS} 133}$ flies lack the A-type $\mathrm{K}^{+}$ current in muscle (Wu and Haugland, 1985; Solc et al., 1987 ) and have abnormally prolonged action potentials in interneurons (Tanouye and Ferrus, 1985) suggesting that the $\mathrm{Sh}^{\mathrm{KS} 133}$ mutation leads to non-functional $\mathrm{K}^{+}$channels. This proposition was tested in the X.laevis oocyte expression system. A replica of the $S h^{\mathrm{KS} 133}$ mutation was introduced into ShA2 cDNA (for nomenclature see Baumann et al., 1989 and Materials and methods). After injection into $X$. laevis oocytes the expression of in vitro transcribed ShA2 cRNA (Figure 2) mediates a rapidly inactivating A-type $\mathrm{K}^{+}$ current (Iverson et al., 1988; Timpe et al., 1988a,b). Whereas several independent injections $(n=15)$ for three different ShA2 cRNA preparations always resulted in the expression of the expected rapidly inactivating A-type current, injections $(n=13)$ of three different $S h^{\mathrm{KS} 133} \mathrm{~A} 2$ cRNA preparations did not elicit a measurable outward $\left(\mathrm{K}^{+}\right)$current (Figure 2). Genetically, the $S h^{\mathrm{KS} 133}$ mutation behaves like an antimorph (Ferrus et al., 1990). The mutation cannot be compensated in gene dosage experiments by adding extra doses of the $\mathrm{Sh}^{+}$locus. The most likely explanation for this behaviour is that mutated $S h^{\mathrm{KS} 133} \mathrm{~K}^{+}$ channel subunits assemble into multimeric, aberrant nonfunctional potassium channels (Gisselmann et al., 1989). This hypothesis was tested by coinjecting various mixtures of $S h \mathrm{~A} 2$ and $S h{ }^{\mathrm{KS} 133} \mathrm{~A} 2$ cRNA into X.laevis oocytes (Figure 2). $I_{\mathrm{A}}$ peak amplitudes were measured after each injection using the same amount of cRNA being either ShA2 cRNA alone, a 1:1, a 3:1 and a 5:1 mixture of ShA2 and $S h^{\mathrm{KS} 133} \mathrm{~A} 2$ cRNAs or $S h^{\mathrm{KS} 133}$ A2 cRNA alone. In comparison with the ShA2 cRNA injections, the ones of 1:1 mixtures of $S h A 2$ cRNA and $S h{ }^{\mathrm{KS} 133} \mathrm{~A} 2$ contained $50 \%$ of the original amount of $S h \mathrm{~A} 2$ and so forth. In control experiments, measured $I_{\mathrm{A}}$ peak amplitudes were proportional to the amount of injected ShA2 cRNA (data not shown; comparable control experiments are shown in Figure 5). If the expression of $S h^{\mathrm{KS} 133} \mathrm{~A} 2$ cRNA would not interfere with the expression of ShA2 cRNA, the injection of 1:1 mixture of $S h \mathrm{~A} 2$ and $S h^{\mathrm{KS} 133} \mathrm{~A} 2$ cRNAs should have given $\sim 50 \%$ of the original $I_{\mathrm{A}}$ peak amplitude obtained after injecting ShA2 cRNA alone. Accordingly, the injection of $3: 1$ mixture should have given $\sim 75 \%$ of the original peak amplitude and the one of a $5: 1$ mixture $\sim 83 \%$. In fact injections $(n=22)$ of a 1:1 mixture of ShA2 and $S h^{\mathrm{KS} 133 \mathrm{~A} 2}$ cRNAs gave $20 \%$ of the expected $I_{\mathrm{A}}$ amplitude (Figure 2); injections $(n=31)$ of a 3:1 mixture of $S h A 2$ and $S h{ }^{\mathrm{KS} 133} \mathrm{~A} 2$ cRNAs gave $\sim 55 \%$ and those $(n$ 
$=21$ ) of a $5: 1$ mixture $\sim 73 \%$ of the expected $I_{\mathrm{A}}$ amplitude (Figure 2). These results, obtained by studying the expression of $S h^{\mathrm{KS} 133}$ cRNA in X.laevis oocytes, are in harmony with the genetic and electrophysiological properties of $S h^{\mathrm{KS} 133}$ mutants. Therefore, we conclude that the molecular basis of the $S h^{\mathrm{KS} 133}$ phenotype is the missense mutation in the bend region connecting proposed transmembrane segments $\mathrm{S} 5$ and $\mathrm{S} 6$ of the $\mathrm{Sh} \mathrm{K}^{+}$channel proteins (see Figure 1).

The $S h^{\mathrm{E} 62}$ mutation has been mapped genetically distal to the $S h^{\mathrm{KS} 133}$ mutation (Kamb et al., 1987; Ferrus et al., 1990). Therefore, the $S h^{\mathrm{E} 62}$ mutation should reside somewhere at the edge of the $S h$ core region (exon 15) or even further downstream in exons $16-18$ or $19-21$, which encode the two alternative C-termini of $S h \mathrm{~K}^{+}$channel proteins (Pongs et al., 1988). Action potentials in $S h^{E 62}$ interneurons are irregular, but are not broadened like the ones in $S h^{\mathrm{KS} 133}$ interneurons (Tanouye and Ferrus, 1985). Also, $I_{\mathrm{A}}$ is not eliminated in muscle, but the peak amplitude is significantly smaller than in wild-type (Timpe and Jan, 1987). A $S h^{\mathrm{E} 62}$ genomic DNA library was constructed. The two alternative $3^{\prime}$-ends of the $S h^{\mathrm{E} 62}$ transcription unit (exons 16-21) were sequenced. Comparison of the $S h^{\mathrm{E} 62}$ sequence with that of the parent chromosome indicated one base change ( $G$ to $A$ ) (Figure 3A). As a consequence, the wild type $A G$ acceptor site sequence at the intron/exon 20 border has been mutated to the sequence AA (Figure 3B). In fact, the $S h^{\mathrm{E} 62}$ mutation moves the AG acceptor site by one base pair into the open reading frame of exon 20 . Therefore this mutation would alter the processing of $S h$ mRNA. The two most probable possibilities are: (i) the intron between exons 19 and 20 is not spliced; (ii) the intron between exons 19 and 20 is spliced incorrectly. In the former case, the $S h^{\mathrm{E} 62}$ mRNA should contain the intervening sequence between exon 19 and exon 20; in the latter case, the $S h^{\mathrm{E} 62}$ mRNA should have a size like $S h^{+}$mRNA and would contain a coding sequence with a frame-shift mutation. The two possibilities were distinguished by investigating $\mathrm{Sh}^{+}$and $S h^{\mathrm{E} 62}$ mRNA in a polymerase chain reaction (PCR) (Saiki et al., 1988). Sh mRNAs were transcribed in vitro into cDNAs. They were used as templates in a PCR reaction primed with one primer, complementary to exon 19 , and with a second one, complementary to exon 21 , as illustrated in Figure 4A. The amplification products (Figure 4B) were subcloned and sequenced. The three anticipated sizes of the amplification products were: (i) $1.2 \mathrm{~kb}$, if the introns between exons $19 / 20$ and $20 / 21$ were not spliced, (ii) $0.8 \mathrm{~kb}$, if only the intron between exons 19 and 20 were not spliced, (iii) $0.58 \mathrm{~kb}$, if $S h^{\mathrm{E} 62} \mathrm{mRNA}$ was spliced similarly to $S h^{+}$ mRNA. The $1.2 \mathrm{~kb}$ amplification product was only obtained in a PCR reaction with $S h^{\mathrm{E} 62}$ genomic DNA as template (lane 1 in Figure 4B). On the other hand, the $0.58 \mathrm{~kb}$ amplification product was only obtained with $\mathrm{Sh}^{+}$mRNA as starting material, whereas $S h^{\mathrm{E} 62}$ mRNA yielded the $0.8 \mathrm{~kb}$ amplification product corresponding to the sequence shown in Figure 3B. This sequence contained the intervening sequence between exon 19 and exon 20 . The sequence was identical to that of $\mathrm{Sh}^{+}$DNA except for the mutation in the acceptor site AG (Figure 3A). These results demonstrate that the intervening sequence between exons 19 and 20 is not spliced in $S h^{\mathrm{E} 62}$ mRNA because of a mutation in the acceptor AG sequence and not because of a mutation elsewhere. The derived protein sequence of the unspliced $S h^{\mathrm{E} 62}$ mRNA (Figure 3C) indicates that the mutation leads to an aberrant $\mathrm{C}$-terminus. The predicting reading frame terminates at a stop codon within the intervening sequence between exon 19 and exon 20 . Thus $S h^{\mathrm{E} 62}$ proteins are lacking the last 103 amino acids of the corresponding wild type protein sequence.

We investigated whether the deficient $\mathrm{C}$-terminus in $S h^{\mathrm{E} 62}$ proteins affects the electrophysiological properties of

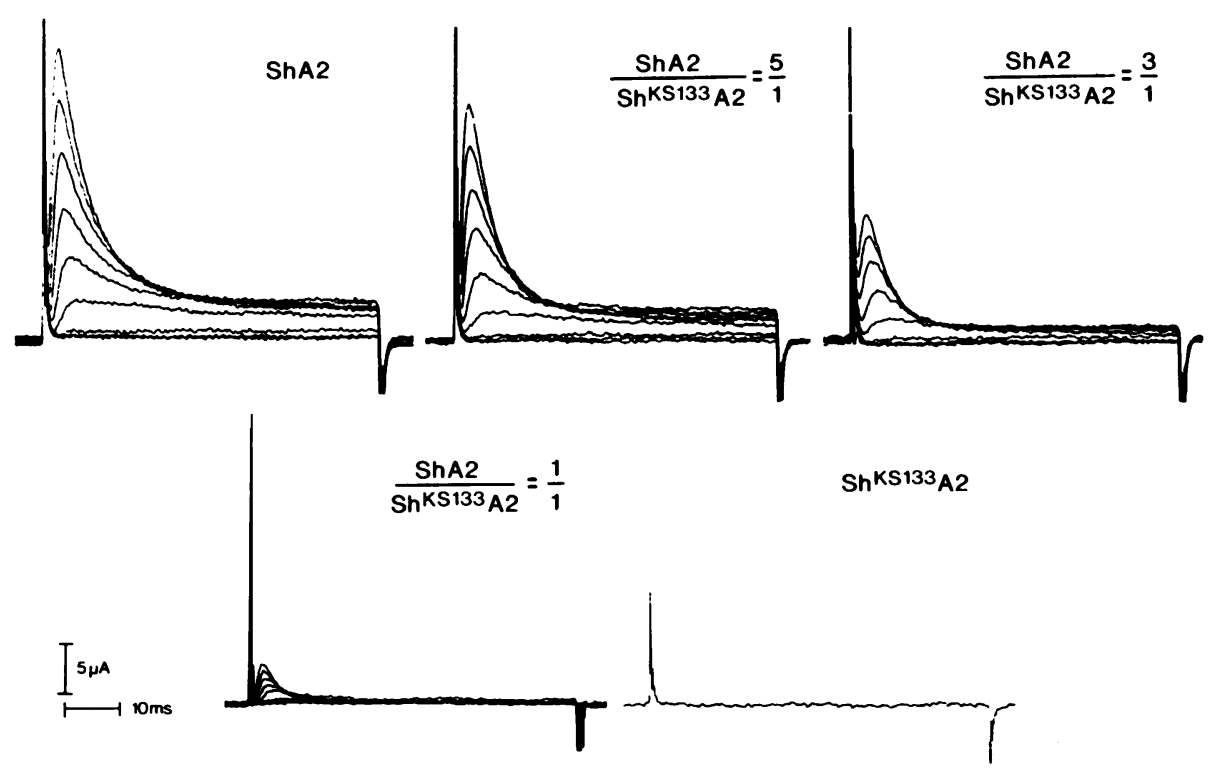

Fig. 2. Expression of transient outward currents in X.laevis oocytes injected with $S h A 2$ and $S h^{\mathrm{KS} 133} \mathrm{~A} 2$ cRNAs synthesized in vitro. Outward currents were recorded in a two electrode voltage clamp configuration. Membrane currents were elicited by potential steps from $-80 \mathrm{mV}$ to levels between $-50 \mathrm{mV}$ and $+20 \mathrm{mV}$, in $10 \mathrm{mV}$ increments. Leak currents have been substracted. Representative current records are shown which were obtained (from left to right and from top to bottom) after the injection into X.laevis oocytes of ShA2 cRNA (ShA2), of a 5:1 mixture, of a 3:1 mixture, of a 1:1 equimolar mixture of $S h A 2$ and $S h{ }^{\mathrm{KS} 133} \mathrm{~A} 2 \mathrm{cRNAs}$ and of $S h{ }^{\mathrm{KS} 133} \mathrm{~A} 2 \mathrm{cRNA}$. Mean amplitudes at $+20 \mathrm{mV}$ test potentials were for $S h A 2$ currents $31.4 \pm 26.7 \mu \mathrm{A}(n=15)$, for $S h \mathrm{~A} 2-S h^{\mathrm{KS} 133} \mathrm{~A} 2(5: 1)$ currents $19.1 \pm 12.8 \mu \mathrm{A}(n=21)$, for $S h \mathrm{~A} 2-S h{ }^{\mathrm{KS} 133} \mathrm{~A} 2(3: 1)$ currents $12.5 \pm$ $7.8 \mu \mathrm{A}(n=31)$, and for $S h \mathrm{~A} 2-S h^{\mathrm{KS} 133} \mathrm{~A} 2(1: 1)$ currents $3.4 \pm 3.5 \mu \mathrm{A}(n=22)$. $S h^{\mathrm{KS} 133} \mathrm{~A} 2 \mathrm{cRNA}$ injections $(n=13)$ did not elicit a measurable current. 
A

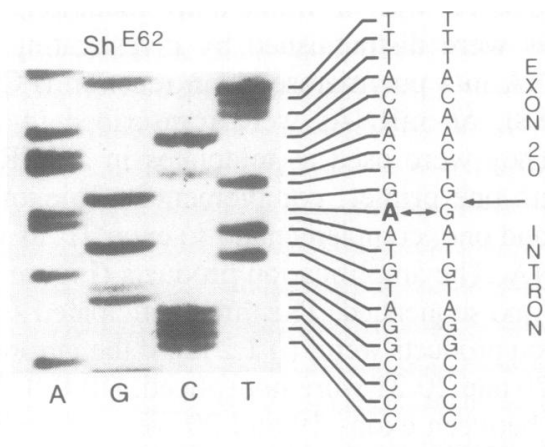

B

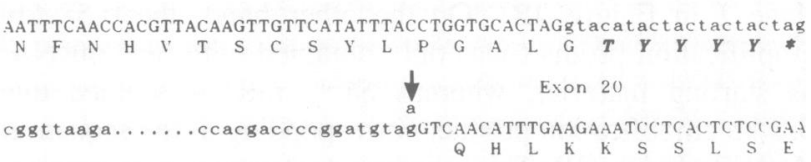

C

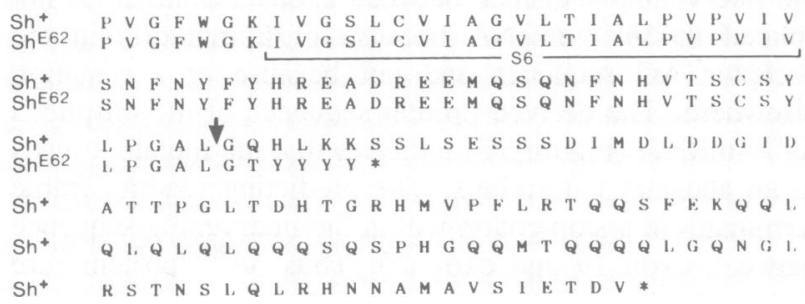

Fig. 3. Molecular basis of the mutation in $S h^{\mathrm{E} 62}$ flies (A) Sequence of the intron/exon 20 border of the $S h^{\mathrm{E} 62}$ transcription unit in comparison with the wild type (Canton S) sequence. The exon 20 sequence corresponds to nucleotides $1538-1547$ of Sh $\alpha$ cDNA (Pongs et al., 1988). The $G$ to $A$ base change between wild type and mutant DNA marked by a double arrow is emphasized by a bold $\mathrm{A}$ in the $S h^{\mathrm{E} 62}$ sequence on the right hand side of the sequencing gel. The sequencing gel for the corresponding wild type sequence is not shown. Arrow at right indicates the intron/exon 20 border. The exon 20 sequence is given above and the intron sequence below the arrow. (B) Effect of the $S h^{\mathrm{E} 62}$ mutation on the predicted $S h$ amino acid sequences. Wild type DNA sequence of exons 19 and 20 is given in capital letters and the connecting intron sequence in small letters. Arrow indicates the site of the $S h^{\mathrm{E} 62}$ mutation. The predicted wild type amino acid sequence is shown below the DNA sequence in the standard one letter code. Bold italic letters illustrate the read-through into the intron sequence in the case of $S h^{\mathrm{E} 62}$ until a nonsense codon is reached (indicated by an asterisk). (C) Comparison of the predicted wild type and $S h^{\mathrm{E} 62}$ amino acid sequences in the C-terminal half of $S h$ proteins Only the C-terminus is shown which is altered in the derived $S h^{\mathrm{E} 62}$ protein sequence. The sequence shown is from amino acid 450 to 616 in ShAl protein (Pongs et al., 1988; Baumann et al., 1989). The proposed transmembrane segment is underlined by a bracket. Arrow indicates the exon 19/20 border in the derived amino acid sequence. Asterisks denote stop codons.

$S h \mathrm{~K}^{+}$channels. It should be noted that $\operatorname{ShA} 2$ contains the alternative C-terminus which is not mutated in $S h^{\mathrm{E} 62}$. Therefore a replica of the $S h^{\mathrm{E} 62}$ mutation was introduced in ShA1 cDNA which encodes the C-terminus mutated in $S h^{\mathrm{E} 62}$ (for nomenclature see Baumann et al., 1989 and Materials and methods). Injections of in vitro transcribed ShAl cRNA $(n=28)$ always resulted in the expression of the expected rapidly inactivating A-type current (Figure 5) similar to that of ShA2 cRNA (Iverson et al., 1988; Timpe et al., 1988). On the contrary, injections $(n=24)$ of three
A

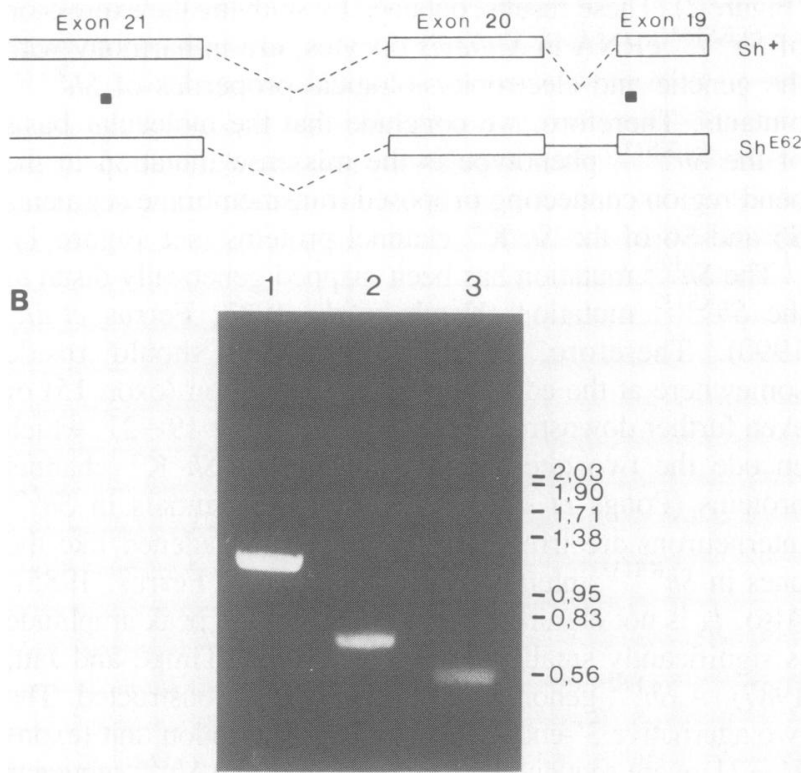

Fig. 4. Consequence of the $S h^{\mathrm{E} 62}$ mutation on splicing $S h$ transcripts. (A) Boxes indicate exons 19,20 and 21 in wild type $\left(\mathrm{Sh}^{+}\right)$and mutant $\left(S h^{\mathrm{E} 62}\right)$ transcripts. The $3^{\prime}-5^{\prime}$ orientation of the exons reflects the proximal/distal direction of transcription of Sh RNA on the Drosophila chromosome (Pongs et al., 1988). Intervening sequences which are spliced are illustrated by dashed lines; the one which is not spliced in $S h^{\mathrm{E} 62}$ transcripts is illustrated by a thin line. Black rectangles denote the location of the oligonucleotide primers in exons 19 and 21 which were used in the polymerase chain reaction. (B) Amplification of $S h^{\mathrm{E} 62}$ genomic DNA (lane 1), of $S h^{\mathrm{E} 62}$ RNA (lane 2) or of $S h^{+}$RNA (lane 3) by a PCR. The sequences from exons 19 to 21 were amplified as illustrated in A. Mol. wt markers are given at the right hand side in kb. Details of the PCR are given in Materials and methods.

different preparations of $S h^{\mathrm{E} 62} \mathrm{~A} 1 \mathrm{cRNA}$ never elicited a measurable outward current (Figure 5). Phenotypically, $S h^{\mathrm{E} 62}$ mutant flies behave like hypomorphs since they appear to produce normal A-channels but in reduced numbers (Timpe and Jan, 1987). In harmony with these data, we found that the $S h^{\mathrm{E} 62}$ mutation affects only one of the two alternative C-termini of the $S h \mathrm{~K}^{+}$channel forming proteins. This is compatible with the observation that $S h$ $\mathrm{K}^{+}$channels are still functional in $S h^{\mathrm{E} 62}$ flies, albeit in reduced number. We have tested whether coinjections of mixtures of $S h \mathrm{~A} 1$ and $\mathrm{Sh}^{\mathrm{E} 62} \mathrm{~A} 1$ cRNA into X.laevis oocytes elicited outward currents of significantly reduced peak amplitudes similar to the coinjections of ShA2 and $S h^{\mathrm{KS} 133} \mathrm{~A} 2$ cRNA. However, we did not observe deviations from the expected $S h A 1$ peak amplitudes which were larger than the normally found standard deviations in the oocyte expression system (Figure 5). Injections of a 1:1, 3:1 or 5:1 mixture of $S h \mathrm{~A} 1$ and $S h^{\mathrm{E} 62} \mathrm{~A} 1$ cRNAs yielded in comparison with the injections of ShAl cRNA peak amplitudes of $\sim 53 \%(n=24), \sim 66 \%(n=21)$ and $\sim 76 \%$ $(n=20)$, respectively. Apparently, the peak amplitudes depend only on the amount of ShAl cRNA injected in each experiment. This suggests that the coinjection of $S h^{\mathrm{E} 62} \mathrm{~A} 1$ cRNA did not interfere with the expression of ShA1 cRNA.

$S h^{5}$ is a particularly interesting mutant because the voltage dependence and the kinetics of $I_{\mathrm{A}}$ in Drosophila muscle are modified by this mutation (Salkoff, 1983; Wu and Haugland, 1985; Haugland and Wu, 1990). Also, interneurons of $S h^{5}$ flies fire repetitive action potentials 


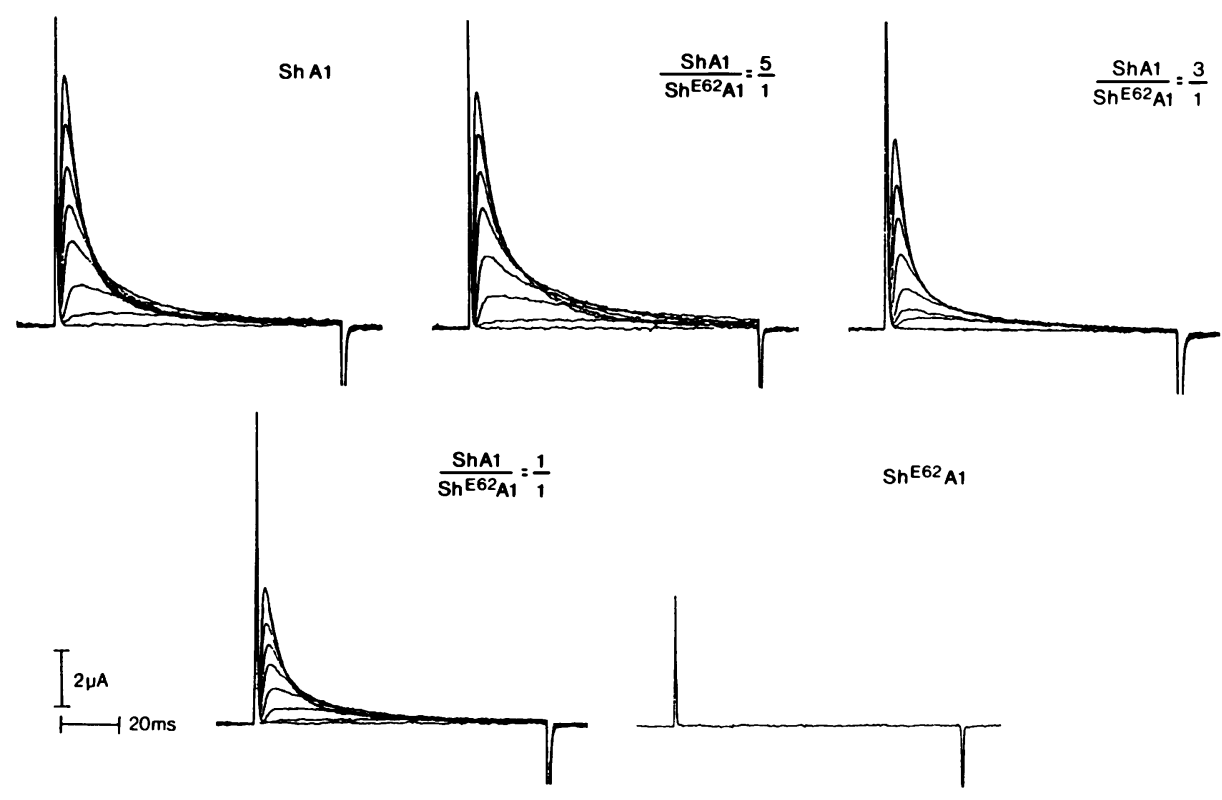

Fig. 5. Expression of transient outward currents in X.laevis oocytes injected with $S h \mathrm{Al}$ and $S h^{\mathrm{E} 62} \mathrm{Al}$ cRNAs synthesized in vitro. Outward currents were recorded in a two electrode voltage clamp configuration. Membrane currents were elicited by potential steps from $-80 \mathrm{mV}$ to levels between $-50 \mathrm{mV}$ and $+20 \mathrm{mV}$, in $10 \mathrm{mV}$ increments. Leak currents have been substracted. Representative current records are shown which were obtained (from left to right and from top to bottom) after the injection into X.laevis oocytes of ShAl cRNA (ShA1), of 5:1 mixtures, of 3:1 mixtures, of 1:1 mixtures of $S h \mathrm{~A} 1$ and $S h{ }^{\mathrm{E} 62} \mathrm{Al}$ cRNAs and of $S h{ }^{\mathrm{E} 62} \mathrm{~A} 1$ cRNA $\left(S h^{\mathrm{E} 62} \mathrm{~A} 1\right)$. Mean amplitudes at $+20 \mathrm{mV}$ test potentials were for $S h \mathrm{Al}$ currents 14.7 $\pm 7.6 \mu \mathrm{A}(n=28)$, for $S h \mathrm{Al}-S h^{\mathrm{E} 62} \mathrm{Al}(5: 1)$ currents $11.2 \pm 6.1 \mu \mathrm{A}(n=20)$, for $S h \mathrm{Al}-S h^{\mathrm{E} 62} \mathrm{Al}(3: 1)$ currents $9.7 \pm 4.3 \mu \mathrm{A}(n=21)$ and for $S h \mathrm{Al}-S h^{\mathrm{E} 62} \mathrm{~A} 1$ (1:1) currents $7.8 \pm 3.8 \mu \mathrm{A}(n=24) . S h^{\mathrm{E} 62} \mathrm{Al}$ cRNA injections $(n=21)$ did not elicit a measurable current.

(Tanouye and Ferrus, 1985). The $S h^{5}$ mutation could not be separated genetically from the $S h^{\mathrm{KS} 133}$ mutation (Ferrus et al., 1990). We hypothesized that this mutation also affects the sequence of the $S h$ core region. A $S h^{5}$ genomic DNA library was constructed and the $S h$ core region was sequenced. Only one sequence alteration was discovered between the core region sequence of the parent Canton $\mathrm{S}$ chromosome and $\mathrm{Sh}^{5}$ DNA (Figure 6A). The detected base change ( $\mathrm{T}$ to $\mathrm{A}$ ) in exon 14 represents a missense mutation, which replaces in the predicted $S h$ protein sequences a phenylalanine (TTT) by an isoleucine (ATT) (Figure 6B). This isoleucine is located in the topological model proposed for $S h$ protein within the putative transmembrane segment S5 as indicated in Figure 6C. The missense mutation is apparently the molecular basis of the $S h^{5}$ phenotype. This proposition was again tested in the $X$.laevis oocyte expression system.

A replica of the $S h^{5}$ mutation was introduced in vitro into ShA2 cDNA. Injections of in vitro transcribed ShA2 or the $S h^{5} \mathrm{~A} 2$ cRNA in X.laevis oocytes gave rise to similar transient outward currents (Figure 7A). In order to compare in greater detail the time course and voltage dependence, currents were recorded from macro-patches on X.laevis oocytes. Normalized conductance voltage relations of the currents indicate that they activate at test potentials of $-40 \mathrm{mV}$ (Figure 7B). However, the voltage dependence of activation for the $S h^{5} \mathrm{~A} 2 \mathrm{~K}^{+}$channels was less steep than the one for $\operatorname{ShA} 2 \mathrm{~K}^{+}$channels. Consequently, $S h^{5} \mathrm{~A} 2 I_{\mathrm{A}}$ reaches the half-maximal conductance at $\sim 7 \mathrm{mV}$ more positive potentials (Table I). This result is comparable with the change in voltage dependence of $I_{\mathrm{A}}$ found in muscle of $S h^{5}$ larvae (Wu and Haugland, 1985; Zagotta and Aldrich, 1990 ), where voltage dependence of $I_{\mathrm{A}}$ activation is shifted $\sim 10 \mathrm{mV}$ to more positive levels. Moreover, the rates of $I_{\mathrm{A}}$ activation were different between $S h \mathrm{~A} 2$ and $S h^{5} \mathrm{~A} 2$ currents (Table I). The rise to peak current from a holding potential of $-80 \mathrm{mV}$ to a test potential of $0 \mathrm{mV}$ required $1.4 \mathrm{~ms}$ for $S h \mathrm{~A} 2$ currents and $0.9 \mathrm{~ms}$ for $S h^{5} \mathrm{~A} 2$ currents. The voltage dependence of prepulse inactivation of $S h^{5} \mathrm{~A} 2$ currents was also altered. $S h \mathrm{~A} 2$ and $S h^{5} \mathrm{~A} 2$ currents were completely inactivated at a test potential of -40 to $-30 \mathrm{mV}$, but the steepness of the voltage dependence of prepulse inactivation was altered in the case of $S h^{5} \mathrm{~A} 2$ (Table I). Similar differences in slopes of $e$-fold $/ \mathrm{mV}$ for $S h^{+}$and $S h^{5}$ $\mathrm{K}^{+}$channels have been reported using whole cell recording techniques on cultured embryonic myotubes from Drosophila (Zagotta and Aldrich, 1990). The acceleration of the rate of recovery from $I_{\mathrm{A}}$ inactivation in muscle of $S h$ pupae is most notable in experimental protocols using prepulse potentials of $-50 \mathrm{mV}$ (Salkoff, 1983). In the oocyte expression system, the difference between the rates of recovery from $S h \mathrm{~A} 2$ and $S h^{5} \mathrm{~A} 2 I_{\mathrm{A}}$ inactivation was largest when potentials of $-40 \mathrm{mV}$ were used (Table I). Under these experimental conditions, $S h^{5} \mathrm{~A} 2$ currents recovered from inactivation twice as fast as $\operatorname{Sh} \mathrm{A} 2$ currents. A detailed description of these experiments will be published elsewhere.

In contrast to the gating behaviour, the single channel conductance of $S h \mathrm{~K}^{+}$channels was not significantly altered by the $S h^{5}$ mutation (Table I). ShA2 as well as $S h^{5} \mathrm{~A} 2$ unitary currents are binomially distributed around a mean of 0.71 and $0.78 \mathrm{pA}$ giving an apparent single-channel conductance of 7.1 and $7.8 \mathrm{pS}$, respectively (Table I). Open duration histograms of $S h \mathrm{~A} 2$ and $S h^{5} \mathrm{~A} 2$ channels at $0 \mathrm{mV}$ are well fitted by single exponential propability density functions with a mean time constant of $1 \mathrm{~ms}$ (data not shown). Also the pharmacology of $S h \mathrm{~A} 2$ and $S h^{5} \mathrm{~A} 2 \mathrm{~K}^{+}$ channels was comparable (Table II). $S h^{5} \mathrm{~A} 2$ channels were slightly more sensitive to 4-aminopyridine (4-AP) and to tetraethylammonium chloride (TEA). Both channels had the same sensitivity or insensitivity towards the toxins charybdotoxin (CTX), dendrotoxin (DTX) and mast cell degranulating peptide (MCDP), respectively. 


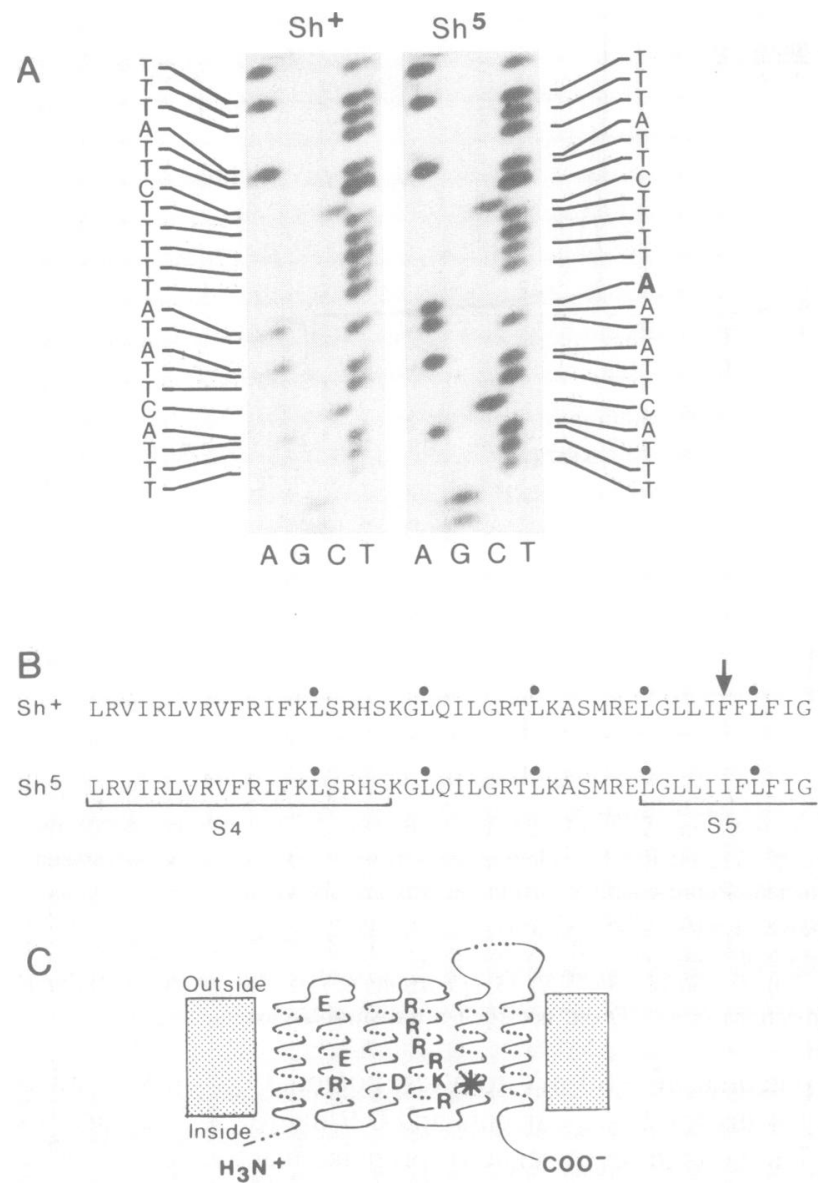

Fig. 6. Molecular basis of the mutation in $S h^{5}$ flies. (A) Sequence of part of exon 14 of the $S h$ transcription unit of Canton S DNA $\left(\mathrm{Sh}^{+}\right)$ and of $S h^{5}$ DNA $\left(S h^{5}\right)$. The sequence corresponds to nucleotides 1149-1170 of Sh $\beta$ cDNA (Pongs et al., 1988). The T to A base change between wild type and mutant DNA is emphasized by a bold $\mathrm{A}$ in the $S h^{5}$ sequence on the right hand side of the $S h^{5}$ sequencing gel. (B) Comparison of the derived $\mathrm{Sh}^{+}$and $S h^{5}$ amino acid sequences. The sequence is given in the standard one letter code and corresponds to amino acids $347-392$ in ShA2 protein (ShA2 is equivalent to ShB, Schwarz et al., 1988). The replacement of phenylalanine (F) by isoleucine (I) in $S h^{5}$ proteins is indicated by an arrow. Proposed transmembrane segments S4 and S5 (Pongs et al., 1988) are underlined by brackets. Dots on top of the amino acid leucine denote a heptad repeat of five leucines indicative of a leucine zipper motif (McCormack et al., 1989). (C) Topological model of a Sh $\mathrm{K}^{+}$channel subunit (Pongs et al., 1988) inserted into the membrane having the $\mathrm{N}$ - and $\mathrm{C}$-termini on the cytoplasmic side of the membrane. The asterisk in proposed transmembrane segment S5 indicates the site of the missense mutation in $\mathrm{Sh}^{5} \mathrm{~K}^{+}$channel subunits. Charged amino acids within segments S2, S3, and S4 are indicated (D, aspartic acid; E, glutamic acid; $\mathrm{K}$, lysine; $\mathrm{R}$, arginine).

\section{Discussion}

\section{Sh mutants and neuronal excitability}

The molecular basis of three $S h$ mutants has been clarified in this report. Replicas of three mutations have been introduced in vitro into $S h A 1$ or $S h A 2$ cDNA, respectively. The expression of the cRNAs after injection into X.laevis oocytes was studied. The results show that phenotypic traits which have been described for each $S h$ mutation under study were reproduced satisfactorily in the X.laevis oocyte expression system. The abnormal neuronal excitability of the $S h$ mutants can now be correlated with structural defects in $S h \mathrm{~K}^{+}$channel subunits. Basically, three different types of action potentials are seen in Sh mutant Drosophila. In each case, abnormalities are limited to action potential repolarization. Different alleles, however, cause differing delayed repolarization and increased action potential durations (Tanouye and Ferrus, 1985). The action potentials of $S h^{\mathrm{KS} 133}$ and $S h^{102}$ have durations increased by a factor of 10 or more, when compared with normal. These two mutants also appear to be the most vigorous leg shakers. They represent extreme forms of the $S h$ defect because in both cases the core region of the $S h \mathrm{~K}^{+}$channels is mutated. Whereas $S h^{\mathrm{KS} 133}$ is a missense mutation (Figure 1), $S h^{102}$ is a nonsense mutation (Gisselmann et al., 1989) within the core region. These two mutations affect all $\mathrm{K}^{+}$channel forming $S h$ proteins. Both $S h$ mutants behave as antimorphs in gene dosage tests (Salkoff, 1983; Ferrus et al., 1990). This behaviour must be due to the interference of non-functional $S h^{\mathrm{KS} 133}$ or $S h^{102}$ A-channel subunits with their normal counterpart according to our previous results with $S h^{102}$ transformants (Gisselmann et al., 1989) and the $S h^{\mathrm{KS} 133} \mathrm{~A} 2-S h \mathrm{~A} 2$ cRNA expression studies in this report. These data suggest that the mutant $S h$ $\mathrm{K}^{+}$channel subunits assemble together with wild type subunits into multimeres which cannot function as $\mathrm{K}^{+}$ channels. In this context it should be noted, that Western blot analysis of membrane proteins of $S h^{\mathrm{KS} 133}$ flies with $S h$ $\mathrm{K}^{+}$channel antibodies has indicated that the mutant $S h^{\mathrm{KS} 133}$ $\mathrm{K}^{+}$channel protein is inserted into neuronal membranes (Barbas et al., 1989).

$S h^{\mathrm{E} 62}$ is a weak $S h$ allele, where action potentials are moderately increased (by a factor of 2-3) compared with normal (Tanouye and Ferrus, 1985). In this case, the mutation does not reside in the core region of Sh proteins. Only one of the alternative C-termini in the $S h$ protein family is affected. Thus, some, but not all members of the $S h$ protein family are non-functional. This observation is in good agreement with the $S h^{\mathrm{E} 62}$ phenotype which behaves like a hypomorph (Timpe and Jan, 1987).

Our results suggest that a mutation in the proposed transmembrane segment $\mathrm{S} 5$ of $\mathrm{Sh}^{5} \mathrm{~K}^{+}$channels is responsible for the generation of multiple spikes following the initial incomplete repolarization of action potentials (Tanouye and Ferrus, 1985). However, it is not clear at present how the abnormal gating behaviour of $S h^{5} \mathrm{~K}^{+}$ channels (Zagotta and Aldrich, 1990) releases Drosophila interneurons to fire repetitively.

\section{Sh mutants and $I_{A}$ in muscle}

The replication of aberrant $S h \mathrm{~K}^{+}$channels in the oocyte expression system also provides the molecular basis of altered $I_{\mathrm{A}}$ observed in muscle cells of $S h$ mutants (Wu and Haugland, 1985). We have clarified why muscle cells in $S h^{\mathrm{KS} 133}$ flies lack active $S h \mathrm{~K}^{+}$channels. In addition, we have shown that a single point mutation is responsible for the various alterations which have been reported for $I_{\mathrm{A}}$ in muscle of $\mathrm{Sh}^{5}$ larvae (Wu and Haugland, 1985) and pupae (Salkoff, 1983). Similar alterations in the voltage dependence of activation and inactivation and also in the rate of recovery from $I_{\mathrm{A}}$ inactivation were observed in the oocyte expression system with the $S h \mathrm{~A} 2$ member of the $S h \mathrm{~K}^{+}$channel family. Presently, we do not know whether this particular member of the $S h \mathrm{~K}^{+}$channel family constitutes the $S h \mathrm{~K}^{+}$ channel in muscle. However, we presume that all members of the $S h^{\mathrm{K}+}$ channel family are similarly affected by the $S h^{5}$ mutation, since it has occurred in the core region of the $S h$ transcription unit. 

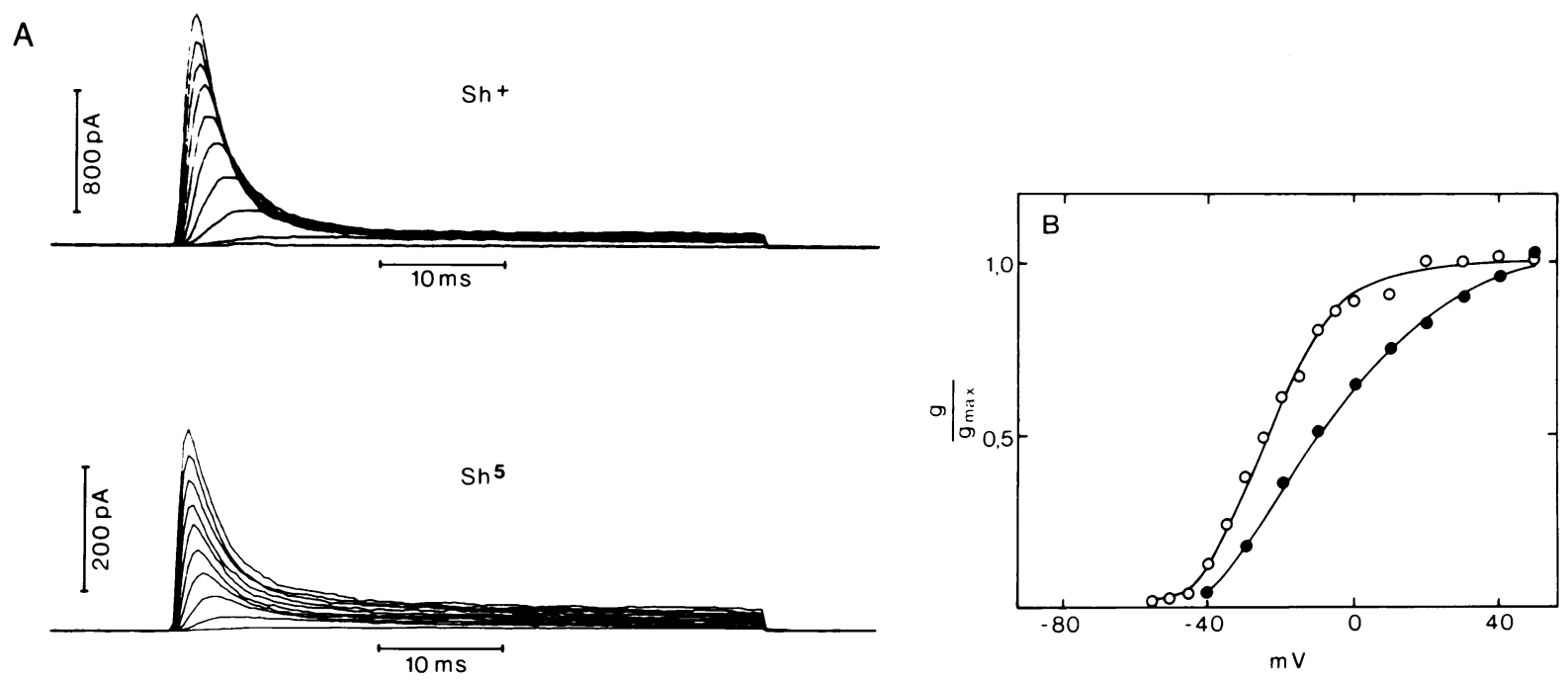

Fig. 7. Expression of transient outward currents in X.laevis oocytes injected with $S h A 2$ or $S^{5}{ }^{5} 2$ cRNA. (A) Outward currents recorded in oocytes injected with $S h \mathrm{~A} 2$ or $\mathrm{Sh}^{5} \mathrm{~A} 2$ cRNA through a macro-patch in the cell-attached configuration. Membrane currents evoked by potential steps from $-100 \mathrm{mV}$ to levels between $-60 \mathrm{mV}$ and $+40 \mathrm{mV}$, in $10 \mathrm{mV}$ increments are shown. Leak and linear capacitive currents, determined from hyperpolarizing steps, have been substracted. (B) Normalized conductance-voltage relations of the $\operatorname{ShA} 2\left(-\bigcirc_{-}\right)$and $S h^{5} \mathrm{~A} 2$ (- $\left.\bullet-\right)$ currents. Peak conductances were calculated from the experiments in A according to equation $g=I_{\mathrm{p}} /\left(V_{\mathrm{m}}-V_{\mathrm{r}}\right)$ in which $I \mathrm{p}$ is the peak current, $V_{\mathrm{m}}$ is the membrane potential during the step, and $V_{\mathrm{r}}$ is the reversal potential of the A-current. Peak conductances were normalized to the maximum conductances. The average reversal potential was assumed to be $-100 \mathrm{mV}$.

Table I. Functional characteristics of $S h^{5} \mathrm{~A} 2$ and $S h \mathrm{~A} 2$ channels expressed in X.laevis oocytes following injection of cDNA

\begin{tabular}{|c|c|c|c|c|c|c|c|}
\hline \multirow{2}{*}{$\begin{array}{l}\text { cRNA } \\
\text { type }\end{array}$} & \multicolumn{3}{|l|}{ Activation } & \multicolumn{2}{|l|}{ Inactivation } & \multirow{2}{*}{$\begin{array}{l}\begin{array}{l}\text { Single } \\
\text { channel currents }\end{array} \\
i(0) \\
(\mathrm{pA})^{\mathrm{f}}\end{array}$} & \multirow{2}{*}{$\begin{array}{l}\begin{array}{l}\text { Recovery from } \\
\text { inactivation }\end{array} \\
\tau \\
(\mathrm{ms})^{9}\end{array}$} \\
\hline & $\begin{array}{l}V_{1 / 2}^{\mathrm{n}} \\
(\mathrm{mV})^{\mathrm{a}}\end{array}$ & $\begin{array}{l}a_{\mathrm{n}} \\
(\mathrm{mV})^{\mathrm{b}}\end{array}$ & $\begin{array}{l}t_{\mathrm{n}} \\
(\mathrm{ms})^{\mathrm{c}}\end{array}$ & $\begin{array}{l}V_{1 / 2}^{n} \\
(m)^{d}\end{array}$ & $\begin{array}{l}a_{\mathrm{n}} \\
(\mathrm{mV})^{\mathrm{c}}\end{array}$ & & \\
\hline ShA2 & $\begin{array}{l}-14.5 \pm 9.8 \\
(9)\end{array}$ & $\begin{array}{l}13.6 \pm 2.1 \\
(9)\end{array}$ & $\begin{array}{l}1.4 \pm 0.5 \\
(9)\end{array}$ & $\begin{array}{l}6.6 \pm 0.9 \\
(2)\end{array}$ & $\begin{array}{l}3.9 \pm 0.6 \\
(2)\end{array}$ & $0.71 \pm 0.13$ & $\begin{array}{l}66.1 \pm 2.5 \\
(3)\end{array}$ \\
\hline$S h^{5} \mathrm{~A} 2$ & $\begin{array}{l}-7.8 \pm 7.6 \\
(7)\end{array}$ & $\begin{array}{l}17.4 \pm 2.5 \\
(7)\end{array}$ & $\begin{array}{l}0.9 \pm 0.2 \\
(7)\end{array}$ & $\begin{array}{l}8.8 \pm 0.9 \\
(7)\end{array}$ & $\begin{array}{l}2.9 \pm 0.3 \\
(7)\end{array}$ & $0.78 \pm 0.11$ & $\begin{array}{l}36.63 \pm 6.6 \\
(2)\end{array}$ \\
\hline
\end{tabular}

Numbers in parenthesis refer to number of experiments.

${ }^{a}$ Refers to test potential in $\mathrm{mV}$ where the conductance increase has reached one-half of its maximal value. The conductance was calculated for each test potential by dividing the current amplitude by the driving force. The potassium reversal potential was estimated to be $-100 \mathrm{mV}$. Ensemble current recording from macro-patches. Voltage steps were made from $-80 \mathrm{mV}$ holding potential.

${ }^{b}$ Refers to slope of normalized conductance-voltage relation. Its value corresponds to the change in test potential (in $\mathrm{mV}$ ) to cause an $e$-fold increase in conductance.

${ }^{c}$ Refers to rise time of ensemble patch currents in ms. It was measured at $+10 \mathrm{mV}$ test potential following step changes from $-80 \mathrm{mV}$ membrane potential. The rise refers to the time the current rises from 10 to $90 \%$ of its final value.

${ }^{\mathrm{d}}$ Refers to prepulse membrane potential in $\mathrm{mV}$ at which the current response to a step to $0 \mathrm{mV}$ test potential is $50 \%$ of its maximal value. Prepulse duration is $1 \mathrm{~s}$. Holding potential $-80 \mathrm{mV}$. Ensemble currents were recorded from macro-patches in the cell attached configuration.

${ }^{\mathrm{e}}$ Refers to slope of steady-stage inactivation $\left(h_{\infty}\right)$ curve. Change in prepulse membrane potential (in $\mathrm{mV}$ ) necessary to cause an $e$-fold reduction in the size of the response to a test pulse to $0 \mathrm{mV}$.

${ }^{t}$ Refers to single-channel current amplitude in $\mathrm{pA}$ at $0 \mathrm{mV}$ membrane potential. The respective chord conductances, assuming a reversal potential of $-100 \mathrm{mV}$ are 7.1 and $7.8 \mathrm{pS}$ respectively.

${ }^{g}$ Refers to time constant of recovery from inactivation at $-40 \mathrm{mV}$ membrane potential as measured in a two pulse experiment. Both test pulses were from a hold potential from -80 to $+20 \mathrm{mV}$ with a duration of $120 \mathrm{~ms}$. To estimate the time constant the times between the pulses was varied.

\section{Implications for $\mathrm{K}^{+}$channel structure}

The sequences of voltage-gated $\mathrm{K}^{+}$channels which have been cloned and expressed so far indicate that these channels have a common architectural design (Stühmer et al., 1989a; Butler et al., 1989; Yokoyama et al., 1989). Possibly, they possess six membrane-spanning helices which are oriented in a pseudosymmetric fashion across the membrane (see Figure 1). The $\mathrm{N}$ - and $\mathrm{C}$-terminal ends would be located in this topology at the intracellular side. Two sequence motifs of five amino acids each are present in every $\mathrm{K}^{+}$channel sequence known so far. One sequence motif (EYFFD) is located 89 amino acids in front of segment S1; the other sequence motif (MTTVG) is located in the bend region between proposed transmembrane segments S5 and S6 (Frech et al., 1989; Yokoyama et al., 1989). Given the topological model of $\mathrm{K}^{+}$channels (Figure 1), the EYFFD sequence motif is located intracellularly and the MTTVG sequence motif extracellularly. The ubiquitous occurrence of these two sequence motifs in $\mathrm{K}^{+}$channel sequences suggests that they fulfill an essential structural role in $\mathrm{K}^{+}$ channel function. This proposition is supported by our finding that the $S h^{\mathrm{KS} 133}$ mutation has occurred in the MTTVG sequence. In the absence of structural information, we cannot exclude that the $S h^{\mathrm{KS} 133}$ mutation may result in an overall conformational change of the $\mathrm{K}^{+}$channel. However, in vitro mutagenesis studies on the charybdotoxin 
Table II. Pharmacological properties of $S h \mathrm{~A} 2$ and $S h^{5} \mathrm{~A} 2 \mathrm{~K}^{+}$channels

\begin{tabular}{llllll}
\hline & $\begin{array}{l}\text { DTX } \\
(\mathrm{nM})\end{array}$ & $\begin{array}{l}\text { MCDP } \\
(\mathrm{nM})\end{array}$ & $\begin{array}{l}\text { TEA } \\
(\mathrm{mM})\end{array}$ & $\begin{array}{l}4-\mathrm{AP} \\
(\mathrm{mM})\end{array}$ & $\begin{array}{l}\text { CTX } \\
(\mathrm{nM})\end{array}$ \\
\hline ShA2 & $>>200$ & $>>1000$ & 17.8 & 5.5 & 4.0 \\
$\mathrm{Sh}^{5} \mathrm{~A} 2$ & $>>200$ & $>>1000$ & 13.8 & 2.7 & 5.5 \\
\hline
\end{tabular}

Doses of various $\mathrm{K}^{+}$channel blockers and toxins giving a $50 \%$ reduction in outward $\mathrm{K}^{+}$currents recorded after $50 \mathrm{~ms}$ of a depolarizing pulse of $+20 \mathrm{mV}$. Currents were recorded using a standard two electrode voltage clamp from oocytes bare of their vitelline envelope. DTX and MCDP did not show an effect at the concentrations given. Values reported are from fits of various inhibition doses to a dose-response function. Before each measurement, 10 identical depolarizations to $+20 \mathrm{mV}$, each one lasting $50 \mathrm{~ms}$ were applied to equilibrate for use dependence.

binding site of $S h \mathrm{~K}^{+}$channels (MacKinnon and Miller, 1989) have indicated that a glutamate residue (E422 of ShA2) is some $10-20 \AA$ distant from the $\mathrm{K}^{+}$channel binding site for charybdotoxin. This toxin blocks $\mathrm{K}^{+}$permeation through the pore of the channel (MacKinnon and Miller, 1989). 18 amino acids away from this glutamate residue occurs the MTTVG sequence motif. We propose that this highly conserved $\mathrm{K}^{+}$channel sequence motif is near or in the externally facing mouth of the $\mathrm{K}^{+}$conduction pathway. Accordingly, the aspartate residue in $S h^{\mathrm{KS} 133} \mathrm{~K}^{+}$channels would obstruct $\mathrm{K}^{+}$permeation through the pore.

The $S h^{5}$ mutation replaces within the proposed transmembrane segment S5 the aromatic amino acid phenylalanine by the aliphatic amino acid isoleucine at a site which is highly conserved within the $\mathrm{K}^{+}$channel superfamily (Yokoyama et al., 1989). This inconspicuous structural alteration has profound effects on the electrophysiological properties of the $S h \mathrm{~K}^{+}$channels. The voltage dependence of activation and inactivation, the rate of activation as well as the rate of recovery from inactivation is accelerated in $S h^{5}$ channels. The changes of these seemingly different properties of the $S h \mathrm{~K}^{+}$channel strongly suggest that the $S h^{5}$ mutation induces a conformational change. It has been proposed that segment S5 is connected with segment S4, the probable voltage sensor of the channel (Stühmer et al., 1989b), via a leucine zipper motif (MacCormack et al., 1989). Transcription factors containing a leucine zipper motif possibly dimerize through leucine-leucine interaction (Landschütz et al., 1988). This dimerization requires the parallel opposition of two linear arrays of leucine heptad repeats (Abel and Maniatis, 1989). Based on the proposed topology of $S h \mathrm{~K}^{+}$channel subunits, the $\mathrm{K}^{+}$channel leucine heptad repeat might form a leucine zipper with adjacent subunits via an intermolecular interaction. Such an interaction could be responsible for a link between the voltage sensing part (segment S4) of the $\mathrm{K}^{+}$channel and the $S h^{5}$ mutation in segment S5. Thereby, voltage dependence and gating behaviour of $\mathrm{Sh}^{5} \mathrm{~K}^{+}$channels might be altered in concert.

\section{$S h^{E 62}$ and the organization of $3^{\prime}$ splice site sequences}

The sequences required for splicing in higher eukaryotes include conserved elements at the $5^{\prime}$ and $3^{\prime}$ splice sites and a less conserved element, the branchpoint sequence, at the site of lariat formation (for review see Steitz et al., 1988). Splicing usually takes place at the first AG downstream from the branch site (Reed and Maniatis, 1985). In most introns, a pyrimidine residue is located immediately upstream of the
AG, adenine residues occur less frequently, and guanine residues are rare (Mount, 1982). It is surprising, therefore, that $S h^{\mathrm{E} 62}$ RNA is not spliced between exons 19 and 20 although the acceptor site AG is shifted one nucleotide downstream because the sequence AGG $\left(\mathrm{Sh}^{+}\right)$has been mutated at AAG $\left(S h^{\mathrm{E} 62}\right)$. Similarly, mutation of CAG to AAG in rabbit globin intron 2 leads to a substantial reduction in the efficiency of lariat formation (Aebi et al., 1986). Apparently, the sequence between branchpoint and $3^{\prime}$ acceptor site plays an important role in the efficency of the splicing reaction (Reed, 1990). In this context, it should be noted that the acceptor site sequence in front of exon 17 of $\mathrm{Sh}^{+} \mathrm{RNAs}$ is AGAG. In this case, the second, and not the first AG is used as $3^{\prime}$ acceptor in the natural splicing reaction indicating that a simple scanning mechanism between branchpoint and $3^{\prime}$ acceptor site does not apply.

\section{Materials and methods}

\section{Sequencing of mutant DNA}

Wild type DNA of the $S h$ locus has been isolated and sequenced as described (Pongs et al., 1988). Genomic $S h^{5}$ and $S h^{\mathrm{KS} 133}$ libraries were prepared with partial $M b o I$ or $E c o$ RI digests of adult DNA inserted into cosPneo cosmid vector (Steller and Pirotta, 1985). Restriction fragments of recombinant cosmids containing exons 7-15 of the $S h$ transcription unit were subcloned into Bluescript (Stratagene) by standard cloning techniques. $S h^{\mathrm{E} 62}$ DNA was digested with BamHI or with EcoRI/HindIII followed by gel electrophoresis of the resulting fragments on $0.8 \%$ agarose gels (Maniatis et al., 1982). Restriction fragments of the expected size according to the restriction map of the $S h$ locus (map coordinates +18 to $+34.5,+32.8$ to +37.3 ) were isolated. Isolated fragments were ligated with corresponding arms of EMBL3 or NM1149 vector (Murray, 1983). Recombinant phages containing $S h^{\mathrm{E} 62}$ DNA encoding exons $16-18$ and 19-21 of the $S h$ transcription unit (Pongs et al., 1988) were isolated. DNA was subcloned into Bluescript (Stratagene). Sequencing of both strands was done according to Sanger et al. (1977) using T7 Sequencing ${ }^{\mathrm{TM}}$ kit (Pharmacia LKB Biotechnology AG) or Sequenase ${ }^{\mathrm{TM}}$ kit (USB Corporation).

\section{In vitro mutagenesis}

For cRNA synthesis $\operatorname{ShA} 2$ was cloned in the expression vector pAS18 (Stocker et al., 1990). The $S h^{5}$ and $S h^{\mathrm{KS} 133}$ mutations were introduced into ShA2 cDNA (Baumann et al., 1989) with the oligonucleotide priming technique (Kramer et al., 1984). Corresponding primers for the two mutations were: GGTTTACTTATAATTTTCTTATTTATAGG $\left(\mathrm{Sh}^{5}\right)$ and CCATGACCACCGATGGATATGGTG $\left(S h^{\mathrm{KS} 133}\right)$. The in vitro mutagenesis was carried out with the site directed mutagenesis kit (Boehringer Mannheim, FRG).

$S h^{5} \mathrm{~A} 2$ and $S h^{\mathrm{KS} 133} \mathrm{~A} 2$ were cloned into the $S m a \mathrm{I}$ restriction site of the expression vector pAS18. For cloning $S h \mathrm{~A} 1$ and $S h^{\mathrm{E} 62}$ we constructed a pAS18- $\alpha_{E}$ clone. This clone was obtained by ligating the $X b a I-E c o R I$ fragment of cDNA $\alpha$ (nt 735-2316 in Pongs et al., 1988) with Xbal/SmaI cut pAS18 after filling in the EcoRI site with DNA polymerase I (Klenow). The construction of pAS18- $\alpha_{\mathrm{E}}$ allowed us to ligate with HindIII/XbaI cut pAS18- $\alpha_{\mathrm{E}}$ the N-terminus of ShAl protein. For this purpose the HindIII site was filled in with DNA polymerase I (Klenow). pAS18-A1 was obtained by ligating the HindIII/XbaI cut pAS18- $\alpha_{\mathrm{E}}$ DNA with the $E c o \mathrm{RI}-\mathrm{XbaI}$ fragment of cDNA $\alpha$ (nt -406 to 735 in Pongs et al., 1988) after filling in its $E c o$ RI site. The $S h^{\mathrm{E} 62}$ mutation was introduced into pAS18-ShA1 which was cut with $A s p 718$ and SacI. It was ligated with an $A s p 718-B g I I$ $S h^{\mathrm{E} 62}$ DNA restriction fragment containing sequences from exon 19 to exon 20 (see Figures 3 and 4) in order to replace the 3'-terminus of ShA1 with the corresponding $S h^{\mathrm{E} 62} 3^{\prime}$-terminus. Before ligation the $S a c$ I site of cut pAS18-ShA1 was filled in with T4 DNA polymerase as well as the BglII site of the $S h^{\mathrm{E} 62}$ DNA restriction fragment.

The mutations $S h^{\mathrm{KS} 133} \mathrm{~A} 2, S h^{5} \mathrm{~A} 2, S h^{\mathrm{E} 62} \mathrm{~A} 1$ were controlled by sequencing the entire coding regions.

\section{Polymerase chain reactions}

mRNA isolated from adult heads $\left(\mathrm{Sh}^{\mathrm{E} 62}\right.$ or $\left.S h^{+}\right)$was transcribed in vitro into cDNA using a cDNA synthesis kit (Boehringer Mannheim). Polymerase chain reactions with genomic DNA or cDNA (Saiki et al., 1985) were performed with GeneAmp ${ }^{\mathrm{TM}}$ DNA Amplification Reagent Kit (Perkin 
Elmer Cetus $)$ in a Perkin Elmer DNA Thermal Cycler $\left(1 \mathrm{~min} 57^{\circ} \mathrm{C}, 2 \mathrm{~min}\right.$ $72^{\circ} \mathrm{C}, 1 \mathrm{~min} 92^{\circ} \mathrm{C}, 30$ cycles). The reaction was primed with primers complementary to sequences in exon 19 (primer 1: CAACCACGTTACAAGTTGTTC) and exon 21 (primer 2: CAAGCTGCGTGAACTGGCACTG).

\section{cRNA synthesis and injection into oocytes}

cRNA was prepared from cDNA as described in Stühmer et al. (1988). After storage at $-20^{\circ} \mathrm{C}$ the cRNA $(0.4 \mathrm{mg} / \mathrm{ml})$ was injected into oocytes of X.laevis (stage $\mathrm{Vb} / \mathrm{VI}$ ) in portions of $\sim 50 \mathrm{nl} /$ oocyte. The expression of $S h \mathrm{~A} 2, S h \mathrm{~A} 1$ and $S h^{5} \mathrm{~A} 2$ channels was detectable in nearly every oocyte on the second day after injection. Our nomenclature of $S h \mathrm{~K}^{+}$channel forming proteins has been described in Baumann et al. (1989). ShAl corresponds to ShA of Schwarz et al. (1988) and ShA2 to ShB of Schwarz et al. (1988). ShA1 and $S h \mathrm{~A} 2$ proteins possess the same N-terminal sequence ('A'), but differ in their C-termini as indicated by the number.

\section{Current recording}

Experiments were carried out in normal frog ringer containing (in $\mathrm{mM}$ ) $\mathrm{NaCl} 115, \mathrm{KCl} 2.5, \mathrm{CaCl}_{2}, 1.8$ HEPES 10 (pH 7.2). In some cases, sodium was partially replaced by the blocking substances 4-aminopyridine (4-AP) and tetraethylammonium chloride (TEA) (Sigma). Dendrotoxin (DTX), mast cell degranulating peptide (MCDP) (gifts from Drs F.Dreye and E. Habermann, Universität Giessen, FRG) and charybdotoxin (CTX) (gift from Dr C.Miller, Brandeis University, USA) were added to the bathing solution.

Whole cell currents were recorded using a two microelectrode voltage clamp circuit. Both current and voltage pipettes were filled with $3 \mathrm{M} \mathrm{KCl}$ and had resistances of $0.5-1 \mathrm{M} \Omega$. The recovery of inactivation was measured by this configuration. To estimate $\tau$ the function $I / I_{\max }=c_{0}-c_{1} * \exp (t / \tau)$ was fitted to the peak maxima at various times. $c_{0}$ equals maximal recovery; $c_{1} \mathrm{I} / \mathrm{I}_{\max }$ at $\mathrm{t}=0$.

Pipettes for macro-patches were made from aluminium silicate glass and had a tip diameter of $\sim 4.6 \mu \mathrm{m}$ (Stühmer et al., 1987). They were filled with the normal bathing solution for cell-attached recording giving a resistance of $0.5-1 \mathrm{M} \Omega$. The intracellular potential was simultaneously measured by a microelectrode to determine the effective transmembrane potential across the patch. The $\mathrm{K}^{+}$channel density was not homogeneous and therefore the oocyte had to be patched on several different places before finding an area of high current density. Stimulation and sampling were done as described (Stühmer et al., 1985). To determine the steady-state activation parameters, the function $G=G_{\text {mas }} /\left\{1+\exp \left[\left(V_{1 / 2}-V\right) / a\right]\right\}$ was fitted to the conductance values at each potential. These conductances were obtained by dividing the peak current by the driving force, assuming a reversal potential of $-100 \mathrm{mV}$ in the cell-attached configuration and a calculated reversal of $-98 \mathrm{mV}$ in the inside-out configuration. Steady-stage inactivation parameters were measured only for the channel inactivating in the ms time scale, ShA2, using prepulses lasting $1 \mathrm{~s}$. The data was analysed by fitting the function $I / I_{\max }=1 /\left\{1+\exp \left[\left(V-V_{1 / 2}\right) a\right]\right\}$ to the data points. Pipettes for single-channel recordings were made from borosilicate glass and had resistances of 3-5 M $\Omega$ when filled with bathing solution. The single-channel current records were stored on video tape and analysed by an interactive semi-automatic procedure. Distributions of single-channel current amplitudes were fitted assuming Gaussian distribution.

\section{Acknowledgements}

We thank Drs F.Dreyer and E.Habermann for the generous gift of DTX and MCDP and Dr C.Miller for the generous gift of CTX. This work was supported by the Leibniz-Förderprogramm (to Dr E.Neher) and grants from the Deutsche Forschungsgemeinschaft (G.Boheim and O.Pongs), the Volkswagen Stiftung (A.Ferrus and O.Pongs), CAYCIT (A.Ferrus)

\section{References}

Abel,T. and Maniatis,T. (1989) Nature, 341, 24-25.

Abrams,T.W. and Kandel,E.R. (1988) Trends Neurosci., 11, 128-135.

Aebi,M., Hornig,H., Padgett,R.A., Reiser,J. and Weissmann,C. (1986) Cell, 47, 555-556.

Barbas,J.A., Rubio,N., Pedroso,E., Pongs, O. and Ferrus,A. (1989) Mol. Brain Res., 5, 171-176.

Baumann,A., Krah-Jentgens,I., Müller,R., Müller-Holtkamp,F., Canal,I., Galceran,J., Ferrus,A. and Pongs,O. (1989) In Maelicke,A. (ed.), Molecular Biology of Neuroreceptors and Ion Channels. Springer-Verlag, Heidelberg, pp. 231-243.

Butler,A., Wei,A., Baker,K. and Salkoff,L. (1989) Science, 243, 943-947.
Crow,T. (1988) Trends Neurosci., 11, 136-142.

Ferrus,A., Barbas,J.A., Galceran,J., Krah-Jentgens,I., de la Pompa,J.L., Canal,I. and Pongs,O. (1990) Genetics, 125, 383-398.

Frech,G.C., Van Dongen,A.M.J., Schuster,G., Brown,A.M. and Joho,R.M. (1989) Nature, 340, 642-645.

Gisselmann,G., Sewing,S., Madsen,B.W., Mallart,A., Angaut-Petit,D. Müller-Holtkamp,F., Ferrus,A. and Pongs,O. (1989) EMBO J., 8, $2359-2364$.

Haugland,F.N. and Wu,C.F. (1990) J. Neurosci., 10, 1357-1371.

Hille,B. (1984) Ionic Channels of Excitable Membranes. Sinauer Sunderland, Massachusetts.

Iverson,L.E., Tanouye,M.A., Lester,H.A., Davidson,N. and Ruby,B. (1988) Proc. Natl. Acad. Sci. USA, 85, 5723-5727.

Kamb,A., Iverson,L.E. and Tanouye,M.A. (1987) Cell, 50, 405-413.

Kamb,A., Tseng-Crank,J. and Tanouye,M.A. (1988) Neuron, 1, 421-430.

Kramer,W.. Drutsa,V., Jansen,H.W., Kramer,B., Pflugfelder,M., and Fritz,H.J. (1984) Nucleic Acids Res., 12, $9441-9456$.

Lanschütz,W.H., Johnson,P.F. and McKnight,S.L. (1988) Science, 240, $1759-1764$

MacKinnon, R. and Miller.C. (1989) Science, 245, 1382-1385.

Maniatis,T., Fritsch,E.F. and Sambrook,J. (1982) Molecular Cloning. A Laboratory Manual. Cold Spring Harbor Laboratory Press, Cold Spring Harbor, NY.

McCormack,K., Campanelli,J.T., Ramaswarmi,M., Mathew,M.K. and Tanouye.M. (1989) Nature, 340, 103.

Mount,S.M. (1982) Nucleic Acids Res., 10, 459-472.

Murray,N. (1983) In Hendrix,R.W., Roberts,J.W., Stahl,F. and Weisberg,R.A. (eds), Lambda II. Cold Spring Harbor Laboratory Press, Cold Spring Harbor, NY, pp. 395-432.

Pongs,O., Kecskemethy,N., Müller,R., Krah-Jentgens,I., Baumann,A., Kiltz,H.H, Canal,I., Llamazares,S. and Ferrus,A. (1988) EMBO J., 7. $1087-1097$

Reed,R. (1990) Genes Dev., 3, 2113-2123.

Reed,R. and Maniatis,T. (1985) Cell, 41, 95-105.

Saiki,R.K., Schorf,S., Faloona,F., Mullis,K.B., Horn,G.T., Ehrlich,H.A. and Arnheim, N. (1988) Science, 230, 1350-1354.

Sanger,F., Nicklen,S. and Coulson,A.R. (1977) Proc. Natl. Acad. Sci. USA, 74, 5463-5467.

Salkoff,L. (1983) Cold Spring Harbor Symp. Quant. Biol., 48, 221-231.

Schwarz,T., Tempel,B.L., Papazian,D.M., Jan,N.J. and Jan,L.Y. (1988) Nature, 331, 137-142.

Solc,C.K., Zagotta,W.N. and Aldrich,R.W. (1987) Science, 236 $1094-1098$

Steitz,J.A., Black,D.L., Gerke,V., Parker,K.A., Kramer,A., Frendewey,D. and Keller,W. (1988) In Birnstiel,M.L. (ed.) Structure and Function of Major and Minor SNURPS. Springer Verlag, Heidelberg, pp. 115-154. Steller,H. and Pirotta,V. (1985) EMBO J., 4, 167-171.

Stocker,M., Stühmer,W., Wittka,R., Wang,X., Müller,R., Ferrus,A. and Pongs,O. (1990) Proc. Natl. Acad. Sci. USA, in the press.

Stühmer,W., Methfessel,C., Sakmann,B., Noda,M. and Numa,S. (1985) Eur. Biophys. J., 14, 131-138.

Stühmer,W., Stocker,M., Sakmann,B., Seeburg,P., Baumann,A., Grupe,A. and Pongs,O. (1988) FEBS Lett., 242, 199-206.

Stühmer,W., Ruppersberg,J.P., Schröter,K.H., Sakmann,B., Stocker,M. Giese,K.P., Perschke,A., Baumann,A. and Pongs,O. (1989a) EMBO J. 8, 3235-3244

Stühmer,W., Conti,F., Suzuki,H., Wang,X., Noda,M., Yahagi,M., Kubo,H. and Numa,S. (1989b) Nature, 339, 597-609.

Tanouye,M.A. and Ferrus,A. (1985) J. Neurogenet., 2, 253-271.

Tanouye,M.A., Ferrus,A. and Fujita,S.C. (1981) Proc. Natl. Acad. Sci. USA, 78, 6548-6552.

Timpe,L.C. and Jan,L.Y. (1987) J. Neurosci., 7, 1307-1317.

Timpe,L.C., Schwarz,T.L., Tempel,B.L., Papazian,D.M., Jan,Y.N. and Jan.L.Y. (1988a) Nature, 331, 143-145.

Timpe,L.C., Jan, Y.N. and Jan,L.Y. (1988b) Neuron, 1, 659-667.

Wu,C.F. and Haugland.F.N. (1985) J. Neurosci., 5, 2626-2640.

Yokoyama,S., Imoto,K., Kawamura,T., Higashida,A., Iwabe,N., Miyata,T and Numa,S. (1989) FEBS Lett., 259, 37-42.

Zagotta,W. and Aldrich,R. (1990) J. Neurosci., 10, 1799-1810.

Received on July 10, 1990; revised on September 10, 1990

\section{Note added in proof}

Our observations and conclusions and the $S h^{5}$ mutation are in accord with those reported by M.Gautam and M.A.Tanouye which appeared in Neuron 5 (1990), 76-73 after submission of this paper. 